\title{
Seasonal renewal time variability in the Curonian Lagoon caused by atmospheric and hydrographical forcing
}

\author{
Georg Umgiesser ${ }^{1,2}$, Petras Zemlys ${ }^{2}$, Ali Erturk ${ }^{3}$, Arturas Razinkova-Baziukas ${ }^{2}$, Jovita Mèžiné ${ }^{2}$, and \\ Christian Ferrarin ${ }^{1}$ \\ ${ }^{1}$ Institute of Marine Sciences - National Research Council (ISMAR-CNR), Castello 2737/f, 30122 Venice, Italy \\ ${ }^{2}$ Open Access Center for Marine Research, Klaipeda University, H. Manto str. 84, 92294 Klaipeda, Lithuania \\ ${ }^{3}$ Istanbul University, Faculty of Fisheries, Department of Freshwater Biology, Ordu Cad. No: 200 Laleli/İstanbul, \\ 34130 Istanbul, Turkey
}

Correspondence to: Georg Umgiesser (georg.umgiesser@ismar.cnr.it)

Received: 26 July 2015 - Published in Ocean Sci. Discuss.: 27 August 2015

Revised: 6 February 2016 - Accepted: 16 February 2016 - Published: 10 March 2016

\begin{abstract}
The aim of this study was to investigate the variability of the water exchanges in the Curonian Lagoon based on the hydraulic regime and the atmospheric forcings. A finite element hydrodynamic model has been applied to the Curonian Lagoon to simulate the circulation patterns for 10 years. With the help of a transport-diffusion model, the salinity distribution and the renewal times of the Curonian Lagoon have been investigated when forced by river runoff, wind, and Baltic Sea level fluctuations. The hydrodynamic model has been validated using in situ salinity measurements.

Model results show that the variability depends mainly on seasonal changes in hydrographic forcing and on the dominant wind regimes that prevail over the Curonian Lagoon. Exchanges between the southern and the northern part of the lagoon mostly depend on the wind forcing and are much less influenced by the river discharge.

However, when looking at the water renewal time, the most important factor is the river discharge into the lagoon. Other physical forcings only marginally determine the renewal time, and not even ice cover is able to influence it. Even if ice cover strongly inhibits the exchanges between the southern and northern lagoon, it is basically not able to change the absolute value of the renewal times.
\end{abstract}

\section{Introduction}

Lagoons are the most productive coastal habitats on earth. They are, however, also considered to be extremely vulnerable to human impact and future climate change. They have crucial relevance what concerns ecological, social, and economical importance, both in a historical and present day (Gonenc and Wolflin, 2005). Lagoons show extremely varying settings concerning hydrological and biological characteristics.

Lagoons depend crucially on the exchange of their waters with the open sea. Especially in lagoons with no freshwater inputs from the land, the only water renewal mechanisms are the exchanges with the open sea. These exchanges are governed by water level variations (mainly tides and storm surges) and wind forcing (especially in lagoons with more than one inlet).

Morphological constraints, like channels, salt marshes, or solid boundaries, could physically divide tidal wetlands in different sub-basins (e.g., Taranto Seas, Cardellicchio et al., 2015). On the other end, multi-inlet lagoon systems (like the Venetian Lagoon in the northern Adriatic) can be roughly subdivided on the base of the total number of main inlets (Ferrarin et al., 2010).

In lagoons with only one inlet and without internal morphological constraints, its hydrodynamics could be used to characterize several sub-domains. This is the case of the Curonian Lagoon, a trans-national coastal system shared by Lithuania in the north and Russia (Kaliningrad Oblast) in the 
south. This lagoon can be formally divided in two sub-basins (Ferrarin et al., 2008): a northern area influenced by both the freshwater flow and the lagoon-sea exchange and a southern basin where hydrodynamics is mostly influenced by the wind.

Understanding the degree and variability of water exchange between the different sub-basins is crucial for describing the temporal and spatial ecological status lagoons (Lucas et al., 2009; McLusky and Elliott, 2004; Andutta et al., 2014). Such a hydraulic partitioning is often used to delineate administrative water basins with different physical, chemical, and biological characteristics, as requested by the Water Framework Directive (WFD) (CEC, 2000).

The Curonian Lagoon in this aspect is quite an atypical lagoon. It is characterized by the fact that a major river directly discharges into the basin, with a climatological average of $21.8 \mathrm{~km}^{3}$ per year $\left(700 \mathrm{~m}^{3} \mathrm{~s}^{-1}\right)$ (Jakimavičius, 2012). This river input makes it basically a freshwater lagoon. Other lagoons in Europe with a strong freshwater discharge similar to the Curonian Lagoon are the Oderhaff in the southern Baltic Sea (Radziejewska and Schernewski, 2008) and the RazelmSinoe lagoon system in the Danube delta (Vadineau et al., 1997). The Curonian Lagoon is also characterized by the absence of tidal action, because tides in the eastern Baltic Sea are of negligible magnitude.

The Curonian Lagoon has been studied by previous modeling applications starting from 2008. Ferrarin et al. (2008) have studied the general circulation of the Curonian Lagoon with a 2-D finite element model. They also studied the residence time distribution for 1 year and finally used these results to carry out a zonation of the lagoon. Hydrodynamic models focusing mainly on investigation of water currents were developed for the Curonian Lagoon by Davuliene et al. (2002), Raudsepp and Kouts (2002), and Ferrarin et al. (2008).

In recent years the salinity distribution has been studied (Zemlys et al., 2013). In this application the model SHYFEM (Umgiesser et al., 2004) has been applied in a 3-D setup. Even if the lagoon is rather shallow, a discretization of the vertical dimension is needed to adequately describe the twodirectional flow in the Klaipeda Strait and the intermittent saltwater intrusion events into the lagoon.

In this study we use validated numerical models to investigate the seasonal and inter-annual variability of the water exchange and water renewal time due to hydrological, atmospheric, and open-sea forcings. The water renewal time (WRT) has been studied with a 3-D application of SHYFEM. It is therefore a new development starting from the work of Ferrarin et al. (2008) computing the WRTs in a 3$D$ mode. The work focuses especially on forcing mechanisms that determine the exchange and the variability of fluxes and WRTs over 10 years between 2004 and 2013.

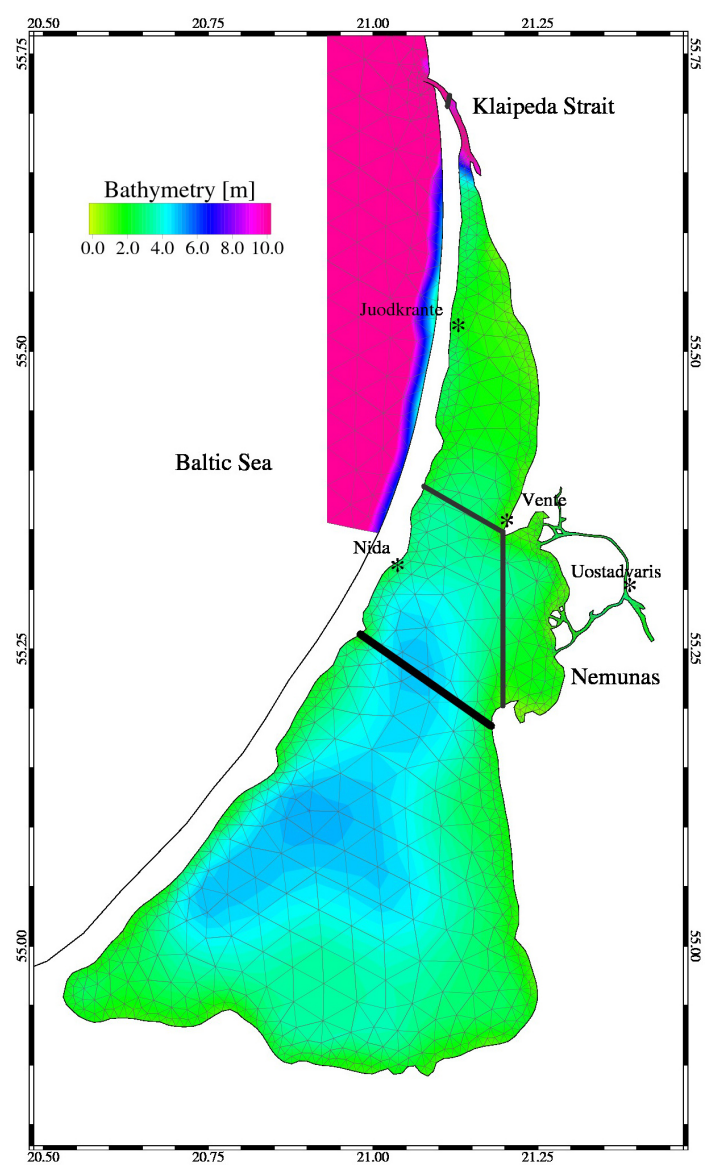

Figure 1. The setting of the Curonian Lagoon showing its bathymetry. Superimposed is the used numerical grid. The thick black line indicates the division into northern and southern subbasin when computing the WRT. This section, called the southern section, is also used for computing the fluxes between the north and the south basins. The three thinner lines are the other flux sections and are named (from north to south) Klaipeda Strait, Vente, and Nemunas. An asterisk marks the stations where ice data have been measured (Juodkrantè, Nida, Vente, Uostadvaris).

\section{Materials and methods}

\subsection{The study site}

The Curonian Lagoon is a coastal lagoon created by the long shore sediment transport in the eastern Baltic Sea (Fig. 1). It is a trans-national lagoon shared by Lithuania in the north and Russia in the south. Its only inlet is situated in the northern (Lithuanian) part. The total area of the lagoon is approximately $1584 \mathrm{~km}^{2}$, the volume is $6.3 \mathrm{~km}^{3}$, its length is $93 \mathrm{~km}$, maximum width is $46 \mathrm{~km}$ in its southern part, and mean depth is $3.8 \mathrm{~m}$ (Žaromskis, 1996).

The dynamics is dominated by the river discharge with a climatological average of $21.8 \mathrm{~km}^{3} \mathrm{yr}^{-1}\left(700^{3} \mathrm{~s}^{-1}\right.$ ) (Jakimavičius, 2012). More than $90 \%$ of this amount is con- 
tributed by the Nemunas river that discharges into the central and northern part of the lagoon.

Every year the rivers carries the amount of fresh water about 4 times the lagoon volume. Therefore, the southern and central parts of the lagoon are fresh water (average annual water salinity is $0.08 \%$ ), while the northern part has an average annual water salinity of $2.45 \%$, with irregular salinity fluctuations of up to $7 \%$ due to Baltic water intrusion (Dailidienè and Davulienè, 2008).

Therefore the Curonian Lagoon is a transitory freshwater basin; due to the inflowing rivers the average water level in the lagoon is normally higher compared to the sea level of the Baltic Sea.

\subsection{Data}

For the calibration and validation results of salinity, a data set of daily measurements performed by the Marine Research Department of Lithuanian Environmental Protection Agency, linked to the Lithuanian Ministry of Environment, for the period 2004-2010 for the northern part of the Curonian Lagoon (Juodkrantė and Klaipèda Strait) was used. Daily river discharges were provided by Lithuanian hydro-meteorological service. The freshwater input into the Curonian Lagoon was considered as the sum of the discharge of its major rivers (Nemunas near Smalininkai, Minija, Šešupè, Jūra, Šešuvis, Deima) (Jakimavičius, 2012). In Fig. 2a the Nemunas discharge together with the Minija River is shown. Together both rivers make up more than $95 \%$ of the total discharge into the Curonian Lagoon (Zemlys et al., 2013).

Open-sea boundary water temperature, salinity, and water levels were obtained by three different sources. For the year 2004-2006 the boundary data were taken from the operational hydrodynamic model MIKE21 provided by the Danish Hydraulic Institute (DHI). For the year 2007-2009 the data were obtained by spatial interpolation of 1 nautical mile spatial resolution forecasts by operational hydrodynamic model HIROMB (Funkquist, 2003) provided by the Swedish Meteorological and Hydrological Institute. For the years 20102013 the data were taken from the model MOM (Modular Ocean Model) provided by the Leibniz Institute for Baltic Sea Research in Warnemünde, Germany. Meteorological forcing fields were obtained by forecasts of the operational meteorological model HIRLAM (http:www.hirlam.org) provided by the Lithuania hydro-meteorological service for the year 2009-2010. For other years data from European Centre for Medium-Range Weather Forecasts (ECMWF, http: //www.ecmwf.int) were used.

Finally, ice data were available only for the years 20072010. These data were provided by the Marine Research Department of the Environment Protection Agency of Lithuania. Ice thickness and ice concentration has been measured daily at four points inside the lagoon (Juodkrante, Nida, Ventè and Uostadvaris, see Fig. 1 for the location of the stations). The ice concentration is a value between 0 (ice free)

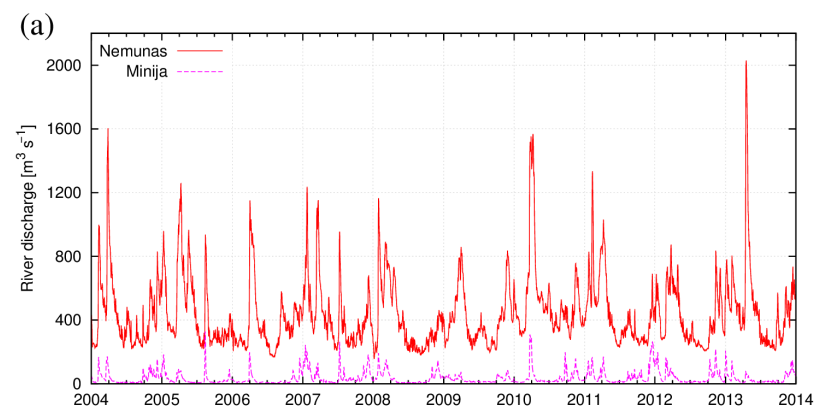

(b) Juodkrante $\square \quad$ Nida $\square$ Uostadvaris $\square \quad$ Vente $\square$

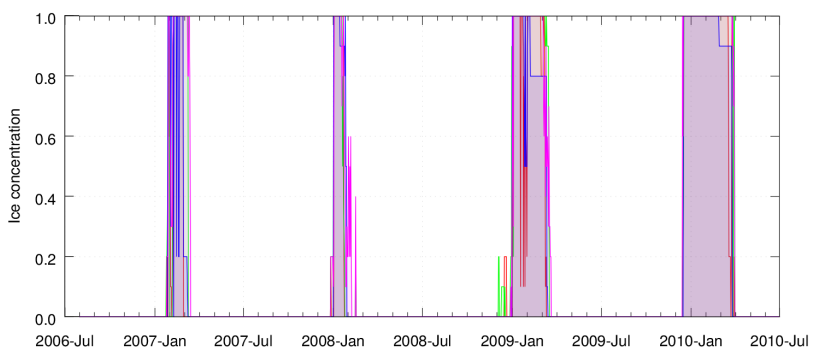

Figure 2. River discharge from 2004 to 2014 into the Curonian Lagoon (a) and measured ice concentration in the years 20072010 (b). In the discharge panel only Nemunas and Minija are shown. The contribution of all other rivers is less than $5 \%$. The ice data show that the freezing and melting happens very fast (on the order of days).

and 1 (fully ice covered) and can be a fractional number. The ice concentration for the years 2007-2010 is shown in Fig. 2b. Please note that, due to the shallowness of the lagoon, freezing (and melting) happens in a short period (days) and once the lagoon is frozen the ice is land locked, not transmitting any wind stress to the underlying water. The Baltic Sea has been considered ice free for all the simulations.

\subsection{The numerical modeling framework}

The framework of numerical models (SHYFEM, http://www. ismar.cnr.it/shyfem) was applied to the domain that represents the Curonian Lagoon and coastal area of the Baltic Sea (Fig. 1). These models consist of a finite element 3-D hydrodynamic model, a transport and diffusion model, and a radiation transfer model of heat at the water surface. SHYFEM was successfully applied to many coastal environments (Ferrarin and Umgiesser, 2005; Ferrarin et al., 2010, 2013; Bellafiore et al., 2011; De Pascalis et al., 2012; Zemlys et al., 2013; Umgiesser et al., 2014).

The model resolves the 3-D primitive equations, vertically integrated over each layer, in their formulations with water levels and transports. The horizontal spatial discretization of the unknowns is carried out with the finite element method, which is especially well suited to describe the complex morphology of the investigated coastal system. In the vertical the water depth is divided into terrain following sigma levels. For 
Table 1. Summary of simulations carried out. The first two simulations are idealized simulations to investigate the exchange capabilities depending on wind and river discharge. The other simulations are simulations with real forcings.

\begin{tabular}{lll}
\hline Name & Period & Description \\
\hline \multicolumn{3}{l}{ Sensitivity simulations with idealized forcings } \\
\hline $\begin{array}{l}\text { Wind } \\
\text { Discharge }\end{array}$ & $\begin{array}{l}\text { 36 days } \\
\text { 250 days }\end{array}$ & $\begin{array}{l}\text { Only wind forcing, the wind rotates over } 360^{\circ} \\
\text { Only freshwater discharge, the discharge varies from } 0 \text { to } 2500 \mathrm{~m}^{3} \mathrm{~s}^{-1}\end{array}$ \\
\hline 10-year simulations with real forcings \\
\hline Reference & 10 years & Reference simulation (used also for validation) \\
Ice & 10 years & As reference, but with ice cover in the years 2007-2010 \\
No level & 10 years & As reference, but without water level variation in the Baltic Sea \\
No river & 10 years & As reference, but without river discharges \\
No baroclinic & 10 years & As reference, but without baroclinic forcing \\
\hline
\end{tabular}

the computation of the vertical viscosities and diffusivities, a turbulence closure scheme is used. This scheme is an adaptation of the $\mathrm{k}-\varepsilon$ module of GOTM (General Ocean Turbulence Model) described in Burchard and Petersen (1999).

The presence of ice has been simulated by weighting the wind drag coefficient by the fractional ice concentration. This corresponds to scaling the momentum input through the surface by the area free of ice. Where ice concentration equals 1 the momentum transfer to the sea is inhibited. No ice-ocean stress is considered in this study. Ice concentration is also used to properly calculate the albedo to be used in the heat flux model.

The model also solves the 3-D advection and diffusion equation to compute water temperature and salinity. The transport and diffusion equation is solved with a firstorder explicit scheme corrected by a total variation diminishing (TVD) method. A more detailed description of the model equations and of the discretization method is given in Umgiesser et al. (2004) and its 3-D implementation to the Curonian Lagoon in Zemlys et al. (2013).

The SHYFEM model has been applied previously to the Curonian Lagoon and has been validated in previous works reproducing water level, water temperature, salinity fluctuations, and the structure of the flow in the Klaipeda Strait (Ferrarin et al., 2008; Zemlys et al., 2013). The reader can refer to Zemlys et al. (2013) for further details on model application and validation in the Curonian Lagoon.

\subsection{Renewal time computation}

The computation of the water renewal time (WRT) has been done according to the methodology indicated in Takeoka (1984) and subsequent modifications in Cucco and Umgiesser (2006) and Cucco et al. (2009). A conservative tracer is released in the whole Curonian Lagoon, with the exception of the Baltic Sea. The model solves the 3-D advection and diffusion equation to compute the tracer dispersal using a first-order explicit scheme based on the total variation di- minishing (TVD) method. The fate of this tracer is followed and the WRT is computed either through integration of the remnant function (concentration divided by initial concentration, a value between 0 and 1) or by fitting the logarithm of the tracer value in every point to a straight line (Umgiesser and Cucco, 2011). The second method gives the possibility of shortening the simulations and stopping them before the concentration arrives at very small values. This procedure allows also restarting the computation at given time periods. In our case we have repeated the computation every 3 months trying to resolve the seasonal variability of the Curonian Lagoon.

\subsection{Simulation setup}

In this application the numerical grid consists of 2027 elements and 1309 nodes. The resolution is much finer in the vicinity of the Klaipeda Strait. A part of the Baltic Sea shelf has also been included in the numerical grid in order to not disturb the computations of the exchanges through the Klaipeda Strait. In the vertical a total of 12 sigma layers have been inserted.

Several numerical simulations have been carried out in this study:

- idealized simulations for investigate the role of different forcing on the water exchange and energy content distribution;

- 10 years of realistic simulations using hydrometeorological forcing for the time period between 1 January 2004 and 31 December of the year 2013.

The characteristics of the performed simulations are summarized in Table 1. The simulation called "Reference" is used as a base line against which all the other simulations have been compared. A part from the ice cover, it is the simulation which contains the complete forcings.

The simulations have been carried out using a maximum time step of $100 \mathrm{~s}$, and the model adopts automatic sub- 
Table 2. Model validation results for salinity. Given are correlation coefficients and root mean square error in \%o. The results refer to the reference simulation, the simulation with ice cover (10 years), only the 4 years where ice cover was available, only 2009 with ice cover, and results from the article Zemlys et al. (2013).

\begin{tabular}{llllll}
\hline & $\begin{array}{l}\text { Reference } \\
\text { (without ice) } \\
2004-2010\end{array}$ & Ice 2004-2010 & Ice 2007-2010 & Ice 2009 & $\begin{array}{l}\text { 2009 from } \\
\text { Zemlys et } \\
\text { al. (2013) }\end{array}$ \\
\hline $\begin{array}{l}\text { Klaipeda } \\
\text { Strait }\end{array}$ & $R=0.584$ & $R=0.596$ & $R=0.641$ & $R=0.675$ & $R=0.74$ \\
\hline Juodkrante & $R=0.398$ & $R=0.410$ & $R=0.427$ & $R=0.499$ & $R=0.67$ \\
& RMSE $=2.068$ & RMSE $=2.024$ & RMSE $=2.063$ & RMSE $=1.759$ & RMSE $=1.6$ \\
\hline
\end{tabular}

stepping over time to enforce numerical stability with respect to advection and diffusion terms. The vertical viscosity and diffusivity are computed by the k-epsilon model GOTM, and the horizontal ones by a Smagorinsky type closure with a parameter of 0.2 according to the value used also in Zemlys et al. (2013). The bottom drag coefficient has been set to a constant standard value of $2.5 \times 10^{-3}$. Finally, the wind drag is being computed by the sea-air interaction model COARE (Fairall et al., 2003). Time series of observed ice concentration have been spatially interpolated onto the finite element grid.

\section{Results}

\subsection{Calibration and validation through salinity}

Even if the calibration and validation has already been carried out in a former work (Ferrarin et al., 2008; Zemlys et al., 2013), we show one more time the validation for the salinity, because the numerical grid has changed between the two applications. In Zemlys et al. (2013) the resolution of the grid was much finer. In the present application a coarser resolution has been used because of the need to run the model for longer time periods.

To drive the model realistic forcing of boundary conditions (water levels, salinity, temperature), meteorological input has been used for the year 2004-2013. For the calibration and validation of modeled salinity, a data set of daily measurements performed by the Marine Research Department of Lithuania Environment Ministry for the period 2004-2010 for the northern part of the Curonian Lagoon (Juodkrante and Klaipeda Strait) was available.

Statistical analysis results for salinity are reported in Table 2 in terms of root-mean-square error (RMSE, in \%o) and correlation coefficient between model results and observations $(R)$. The results showed that the model with ice gives much better results compared to the reference simulation. The correlation coefficient between model results and observations for the period 2007-2010 (when the realistic ice data were used) is $0.641(\mathrm{RMSE}=2.3 \%$ ) in Klaipeda Strait and $0.427(\mathrm{RMSE}=2.1 \%$ ) in Juodkrantè. Still the compar- ison of results with previous studies showed that the highresolution model does a better job in describing salinity variations.

\subsection{Exchange mechanisms between the northern and the southern lagoon}

In a first set of sensitivity simulations the exchange mechanisms between the northern and southern part of the lagoon have been explored. It has been studied how the physical forcing influences and determines the circulation and exchange in the lagoon.

A first simulation explores the dependence on wind direction. The wind speed has been fixed to $5 \mathrm{~m} \mathrm{~s}^{-1}$, which corresponds approximately to the long-term average of winds from all directions. No Nemunas river water discharge has been imposed. Energy content (kinetic and potential) and fluxes between different sub-basins have been computed. The section over which these fluxes have been taken is plotted with black continuous lines in Fig. 1. The results of this experiment are shown in Fig. 3.

Lagoon energy has been computed by excluding the grid area of the Baltic Sea, so only the water circulation and setup of the water level inside the lagoon have been taken into account. Energy is not equally distributed between its kinetic and potential part. The potential energy is normally much higher than its kinetic counterpart. This means that due to the shallow nature of the lagoon the currents contribute much less to the energy budget with respect to the change in water level which accumulates potential energy inside the lagoon.

The energy budget is symmetric with wind speeds of opposite directions (Fig. 3). The minimum of potential energy corresponds to around 90 and $270^{\circ}$, which are easterly and westerly winds. This direction corresponds to a minimum fetch over the lagoon where the wind can act to pile up the water on one side or the other. On the other side, wind directions of 0 and $180^{\circ}$ (northerly and southerly winds respectively) show highest accumulation of potential energy. In this case the potential energy is 50 times higher than in the case of minimum potential energy (please note the logarithmic scale in the figure). 

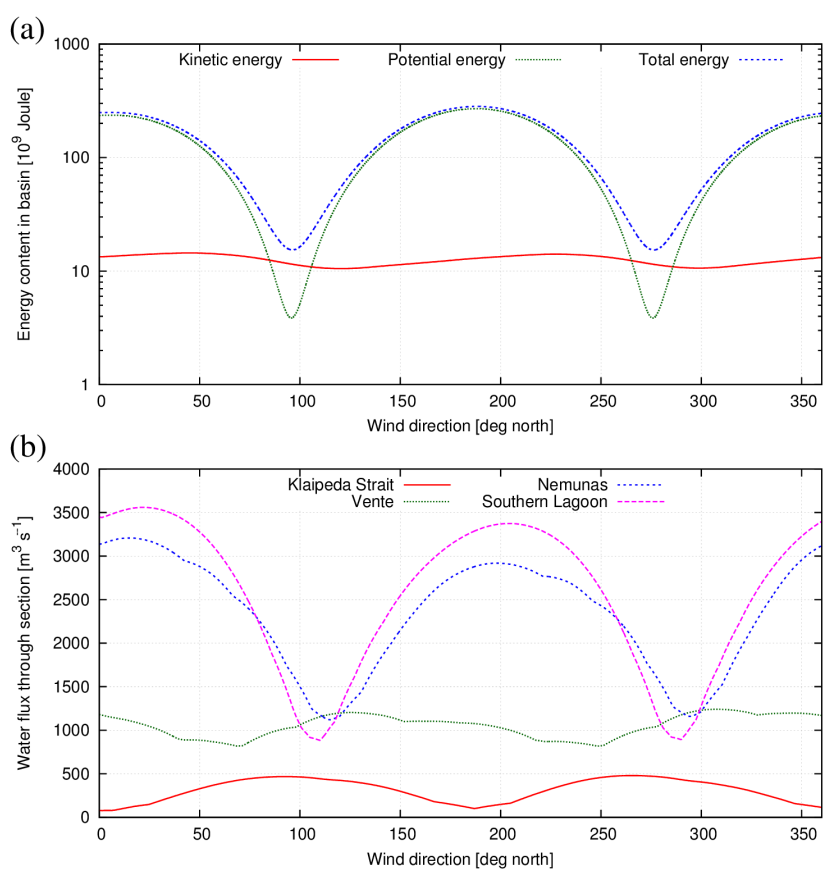

Figure 3. Energy content in basin (a) and fluxes through selected sections (b) depending on the wind direction. For the location of the sections see Fig. 1.

Kinetic energy is differently distributed with wind speed. Its maximum is at around 50 and $230^{\circ}$, which corresponds to $\mathrm{NE}$ and $\mathrm{SW}$ winds. Kinetic energy is much less variable when compared with the potential energy, and it is higher than potential energy only close to where the minimum of potential energy occurs.

In the bottom panel of Fig. 3 fluxes over selected sections (see Fig. 1 for the location of the sections) are presented. Shown are absolute fluxes, so positive and negative fluxes add up to each other. Fluxes through the Klaipeda Strait are maximum at around 100 and $270^{\circ}$, which correspond roughly to the direction of the inlet that connects to the Baltic Sea. Minimum fluxes occur with northerly and southerly winds. The more southerly situated section of Vente shows a similar form with higher fluxes, because it is much wider. Fluxes through the Nemunas section and the southern lagoon section show much higher values, with maxima at around 30 and $200^{\circ}$. This is the wind direction which favors highest exchange between the northern and southern sub-basin in the Curonian Lagoon.

In another simulation only the Nemunas discharge has been taken into account. The simulation has duration of 250 days, while the Nemunas discharge is continuously increased until reaching the value of $2500 \mathrm{~m}^{3} \mathrm{~s}^{-1}$. No wind forcing has been applied. Results are shown in Fig. 4. With a low Nemunas discharge the kinetic energy is higher than the potential energy. This means that with low discharges there is little piling up of the water in front of the Nemunas
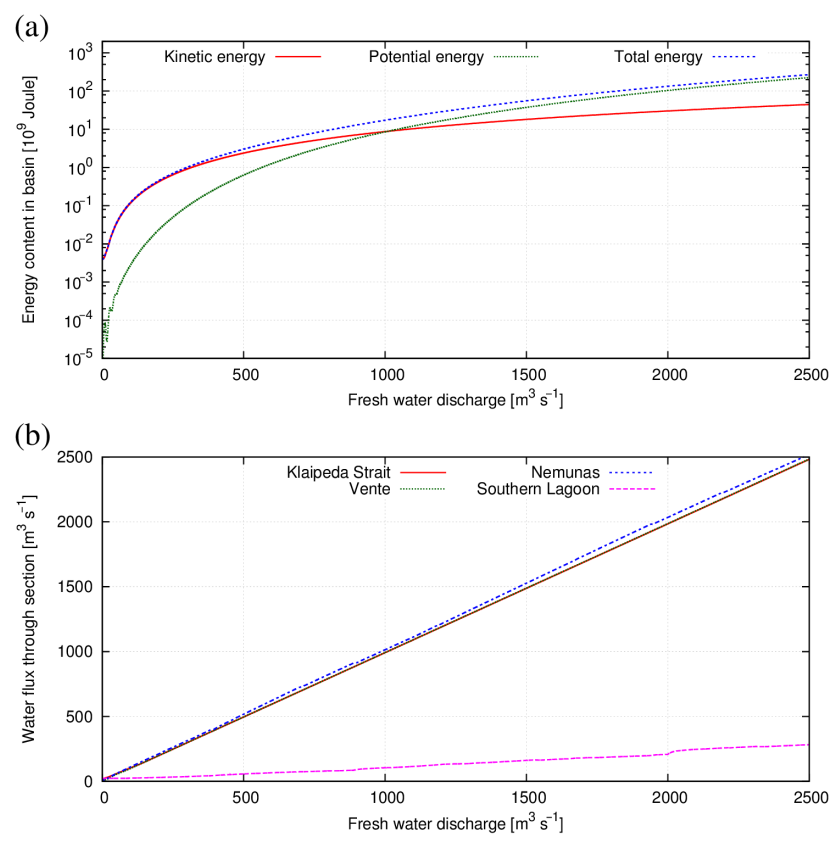

Figure 4. Energy content in basin (a) and fluxes through selected sections (b) depending on the Nemunas discharge. For the location of the sections see Fig. 1.

delta and the water flows freely in the direction of the strait. At higher discharges the ratio is reversed, and potential energy becomes more important, and at very high discharges total energy consists basically only in potential energy. This means that due to the big water masses inflowing the water cannot freely flow to the strait but accumulates close to the Nemunas delta, contributing to a rise in potential energy.

Fluxes for the same simulation are shown in Fig. 4. Not surprisingly, the discharges through Klaipeda Strait, Vente, and Nemunas sections show exactly the same value than the Nemunas discharge. It is however surprising that this Nemunas discharge only influences marginally the fluxes through the southern section. Fluxes still grow linearly with discharge, but they are much lower than through the other sections. The ratio between Nemunas and southern section is about $1 / 8$.

\subsection{General hydrodynamic features of the Curonian Lagoon}

Here we describe some general features of the Curonian Lagoon using the results of the reference simulation. The focus is on the seasonal evolution of circulation and salinity. In Fig. 5 the seasonal circulation is shown (averaged over 10 years). As can be seen, the average circulation (which corresponds to the residual currents) is very stable throughout the seasons. In the north the current direction is from the $\mathrm{Ne}$ munas delta to the north, eventually out of the lagoon. Only in the Klaipeda Strait velocities of $15 \mathrm{~cm} \mathrm{~s}^{-1}$ are exceeded. 

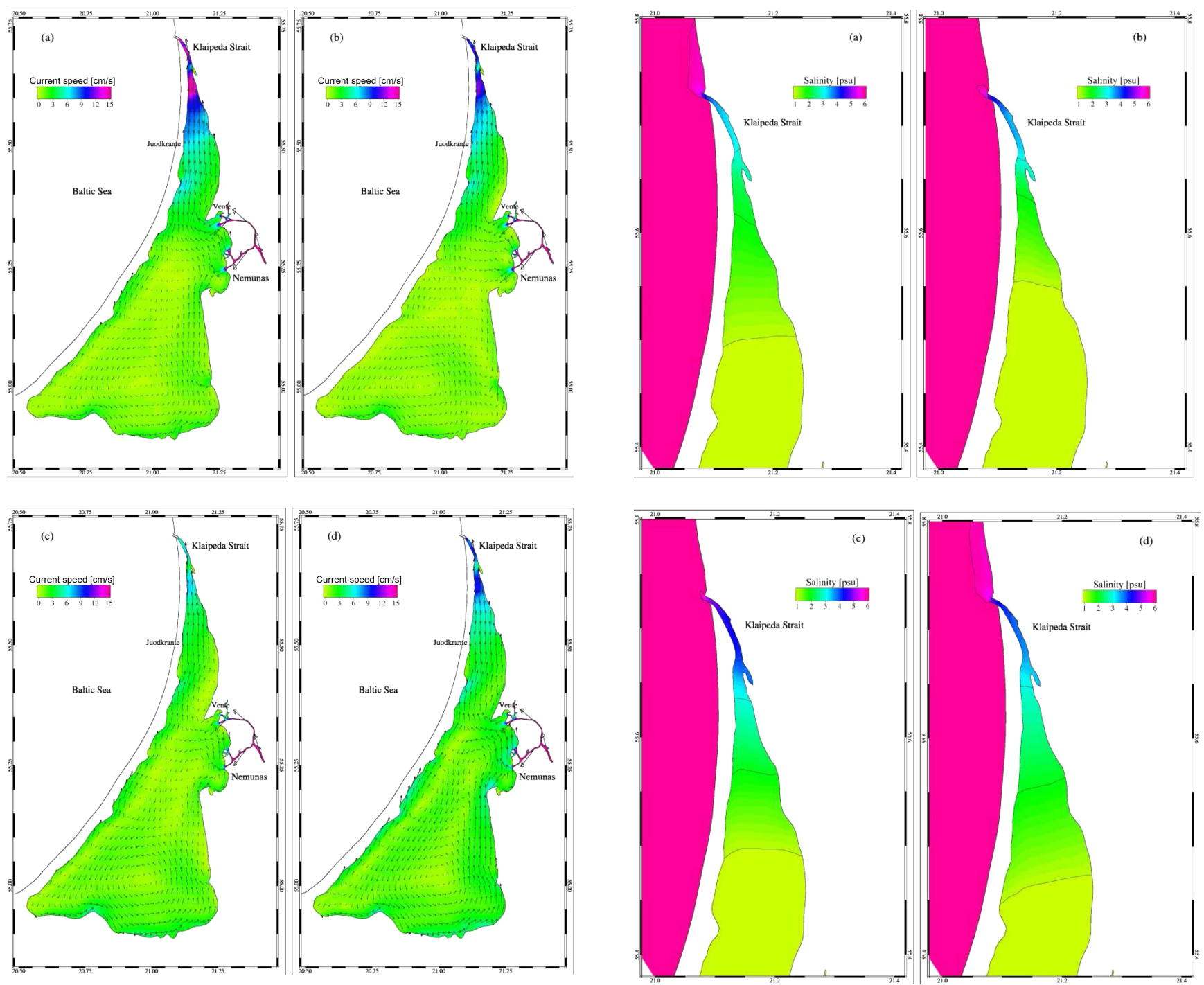

Figure 5. Seasonal maps of residual currents averaged over the years 2004-2014. Maps show winter (a), spring (b), summer (c), and autumn (d).

Velocities in the north are around $5 \mathrm{~cm} \mathrm{~s}^{-1}$, and very low velocities can be found in the southern part, around $2 \mathrm{~cm} \mathrm{~s}^{-1}$. A cyclonic circulation cell is found in all seasons in the southern lagoon. Normally currents along the coast (west and east) are northward, and in the central part they are flowing south. In summertime the northward flow is less strong, and the cyclonic circulation cell is well developed in the south.

Figure 6 shows the seasonal average salinity distribution close to the Klaipeda Strait. The southernmost isoline always indicates the $1 \%$ limit. The strongest gradients can be found close to the end of the strait, just before flowing into the Baltic Sea. The salinity gradient is strongest in wintertime and springtime, but it is quite stable throughout the year. Please remember that this salinity distribution is the average
Figure 6. Seasonal maps of salinity distribution averaged over the years 2004-2014. Maps show winter (a), spring (b), summer (c), and autumn (d). Only the area of the Klaipeda Strait is shown. The southernmost isoline in the figures always indicates $1 \%$.

over many intrusion events, where during these events higher values can be found inside the lagoon.

Finally, temperature distribution in the lagoon throughout the year (not shown) is horizontally homogeneous and follows the yearly cycle, with values between 0 and $25^{\circ}$.

\subsection{Renewal time variability}

As described above the model has been applied to the Curonian Lagoon computing the water renewal time (WRT). Every 3 months the renewal times are computed, and then the concentrations are re-initialized in order to start a new computation period. Renewal times have been computed separately for the northern and southern sub-basin, and for the to- 
Table 3. Summary of the results of the 10-year simulations. Shown are the renewal times for the northern, southern and the whole basin and the absolute fluxes through the southern section together with their standard deviations. Results are for the complete reference simulation, for the 10-year simulation using ice cover in the 4 years where ice cover was available, only for the 4 years with ice cover and only the winter months with ice cover. The other three rows refer to the simulation with no water level variation in the Baltic Sea, with no river discharge and with no baroclinic forcing. Numbers in brackets are the values for the reference run only for the specified period.

\begin{tabular}{lllll}
\hline & WRT north [days] & WRT south [days] & WRT total [days] & $\begin{array}{l}\text { Flux through southern section } \\
{\left[\mathrm{m}^{3} \mathrm{~s}^{-1}\right]}\end{array}$ \\
\hline Reference & $76.5 \pm 21.3$ & $193.5 \pm 55.5$ & $151.7 \pm 45.5$ & $1804.1 \pm 467.5$ \\
Ice 2004-2014 & $76.3 \pm 21.4$ & $195.1 \pm 55.0$ & $152.3 \pm 45.2$ & $1751.4 \pm 474.6$ \\
Ice 2007-2010 & $79.7 \pm 26.3(80.4)$ & $190.8 \pm 48.2(186.6)$ & $148.8 \pm 41.4(147.4)$ & $1770.9 \pm 557.1(1902.6)$ \\
Ice 2007-2010 (only winter) & $51.9 \pm 2.4(52.7)$ & $175.6 \pm 33.1(158.6)$ & $125.1 \pm 20.3(119.1)$ & $1615.8 \pm 831.3(2088.2)$ \\
No level & $81.7 \pm 24.8$ & $208.8 \pm 63.8$ & $156.9 \pm 36.9$ & $1585.4 \pm 461.5$ \\
No river & $211.8 \pm 110.2$ & $1703.5 \pm 1541.0$ & $664.5 \pm 371.7$ & $1834.3 \pm 465.4$ \\
No baroclinic & $76.7 \pm 21.4$ & $192.2 \pm 55.3$ & $151.5 \pm 46.2$ & $1808.4 \pm 464.0$ \\
\hline
\end{tabular}

tal basin. They have also been seasonally averaged over the 10 years of simulation. The result of this run can be seen in Figs. 7 and 8.

Figure 7 shows the seasonal pattern of the WRT averaged over the 10 available years. Figure 7a logarithmic scale has been used in order to be able to show the variability between the short WRTs in the northern and the longer ones in the southern sub-basin. The distribution is very similar between the different seasons. During spring lower WRT can be found close to the Nemunas outflow, due to the higher discharge of the river. In summer the highest values can be found in the south-western basin, and also the eastern shore of the southern lagoon has higher WRTs. However, the average overall pattern does change very little between seasons. In Fig. 8 the high variability of the WRT, both inter-annual and intraannual, can be seen. For both sub-basins the WRT is always lowest during wintertime and highest in the summer. The northern basin also shows low WRT during the spring period, when Nemunas discharge is highest. The southern basin is not influenced by the Nemunas discharge, as already pointed out when discussing the sensitivity simulations.

The northern basin shows WRT of about 77 days (Table 3 ), while the average for the southern basin is nearly 200 days. This behavior can also be observed looking at the frequency curves of the WRT (Fig. 9). These frequency curves show the percentage of water volume of a certain WRT value. The single WRTs have been averaged over the proper season. Clearly visible in all seasons is the first peak at around 50 days that is due to the water masses in the northern basin. A second peak, indicating the water masses of the southern sub-basin, is also visible during winter (180 days) and autumn (around 280 days). It is less pronounced in summer (broad peak at around 300 days) and not visible for springtime.

\subsection{Ice cover influence}

As already mentioned the influence of ice cover on the exchange capabilities and the WRT has been studied. Results can be found in Table 3. If only the 4 years where ice cover was available are studied (third column in the table), it can be seen that the total WRT is barely changing (148.8 days with respect to the reference value of 147.4 days). In the southern basin changes are a bit higher (190.8 days with respect to 186.6 days).

The seasonal variability during the 4 years can be seen in Fig. 8 . In the figure, the actual ice cover has been inserted as a gray band. The winters in 2007 and 2008 are less severe, and hardly any difference in WRT can be found between the results without and with ice cover. The winters of 2009 and 2010 led to a longer period of ice cover, and especially in 2010 some differences in WRT can be seen. As expected WRT, when considering ice cover, goes up in the southern basin, but at the same time lower WRTs can be found in the northern basin.

Finally, analyzing the frequency curves created only for the years 2007-2010, where ice cover was available (Fig. 9, black lines), it becomes clear that the first peak identifying the northern basin is not changing, but the second peak at around 150 days is lower and the distribution is shifting to longer WRTs. This can be seen especially in the very long tail of the winter with ice distribution that is very similar to the distribution in summertime.

\subsection{Dependence on other physical forcings}

Since ice cover (and therefore wind forcing) did not show a strong impact on WRT, it was reasonable to check what other factors would determine the renewal capabilities of the Curonian Lagoon. We decided to test three other physical forcing mechanisms that are influencing the WRT, namely water level variations in the Baltic Sea, the inflow of the Nemunas 

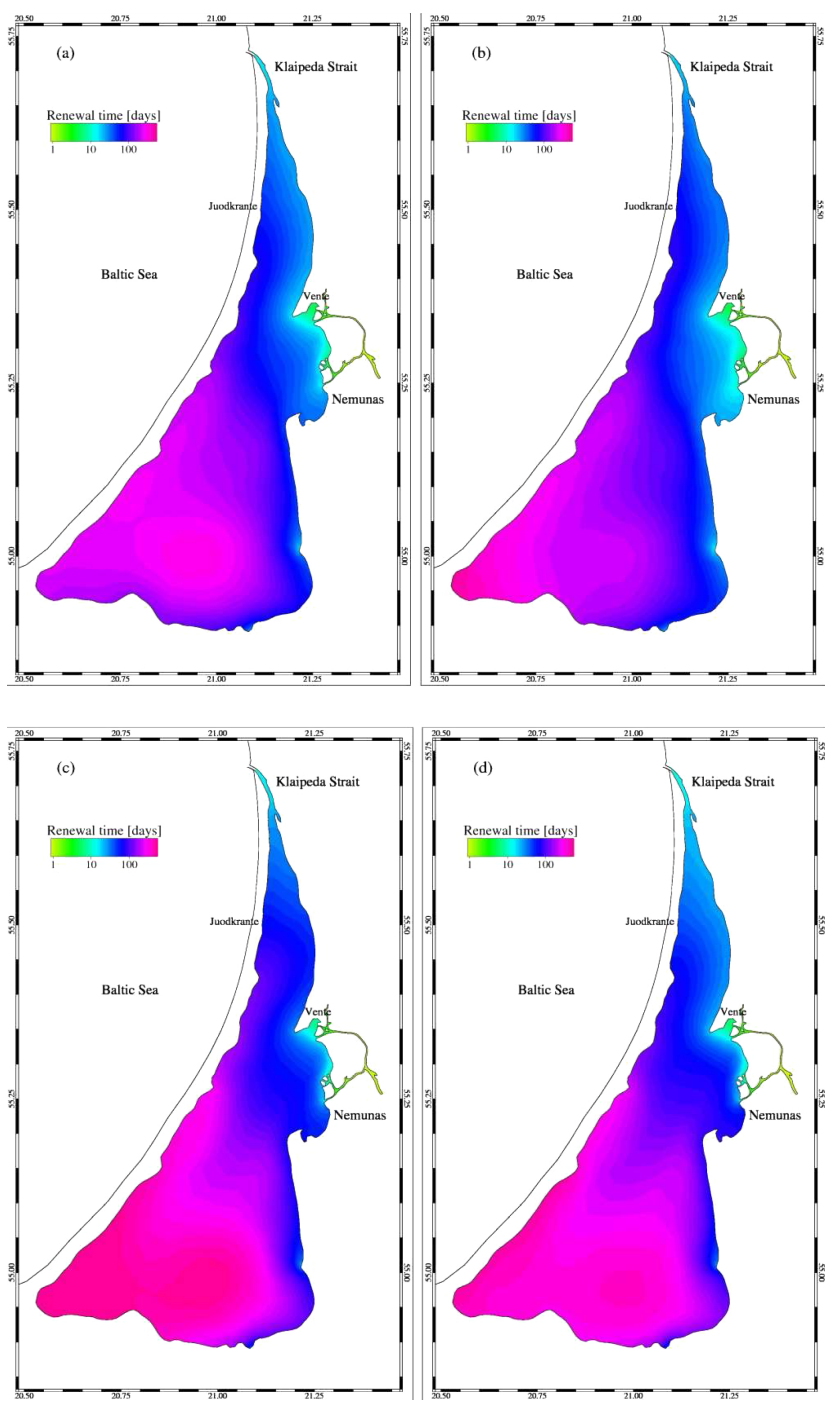

Figure 7. Seasonal renewal time maps averaged over the years 2004-2014. The renewal time is only computed inside the Curonian Lagoon and not in the Baltic Sea. Maps show winter (a), spring (b), summer (c), and autumn (d). Please note the logarithmic color scale.

river, and the role of baroclinic two-layer flow in Klaipeda Strait.

The results of simulation, when the water level variations in the Baltic Sea are set to zero, can be seen in Table 3 and in Fig. 10. Similar changes in WRT can be found in the northern lagoon (7\%) and in the southern one (8\%). Fluxes through the southern section are a little more sensitive to the changes and amount to around $12 \%$. However, as can be seen also in Fig. 11, the changes are slight.

However, if the Nemunas river discharge is switched off, the picture changes radically. Both from Table 3 and Fig. 10 it can be seen that WRTs shift to much higher levels. The WRT in the northern basin becomes similar to the value in the southern one of the reference situation (212 days), and the southern basin shows WRTs of more than 5 years on average,

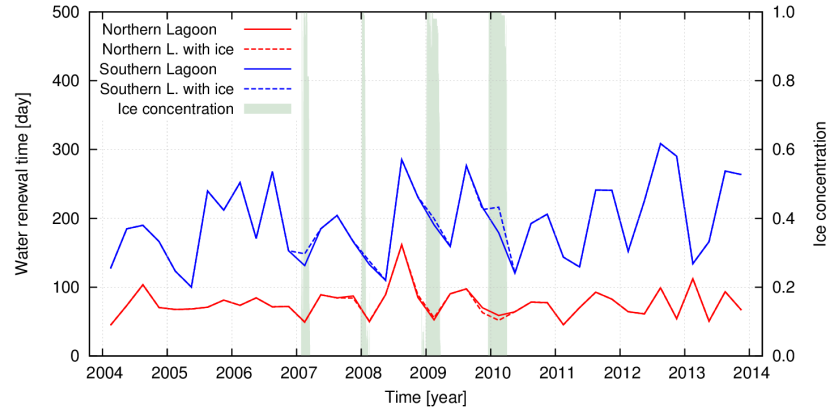

Figure 8. Water renewal times for the northern and southern basin. The WRT is computed every 3 months to obtain a seasonal estimate. WRT is computed with and without ice cover for the years 20072010. The black curve shows the actual ice cover in the Curonian Lagoon.

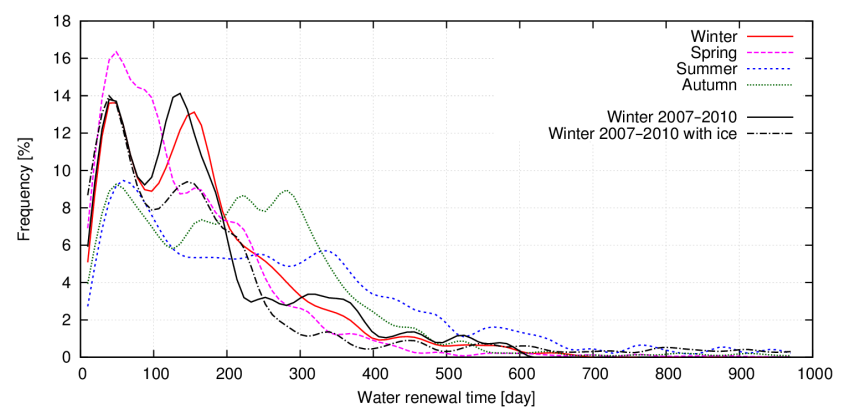

Figure 9. Seasonal frequency curves of WRT. The results refer to the whole 10-year period except the black curves, which indicate the situation with and without ice cover in winter only for years 2007-2010.

with strong inter-annual changes. However, the exchange between the northern and the southern basin only changes by less than $2 \%$.

Finally, a simulation has been carried out that switches off the baroclinic contribution to the equations. The results of this simulation can indicate how important the two-layer density-driven flow in the inlet is for the calculation of the WRT. Results can be again seen in Table 3. Changes with respect to the reference circulation are hardly noticeable, pointing to the conclusion that density-driven flow is not important for the Curonian Lagoon WRT.

\section{Discussion and conclusions}

The simulations that were carried out to study the dynamics of the Curonian Lagoon under changing wind conditions indicated that there are two mechanisms that have to be taken into account. Minimum exchange between northern and southern sub-basin takes place with winds from $\mathrm{N}$ or $\mathrm{S}$. These winds correspond to a minimum exchange through the Klaipeda Strait. This indicates that winds act in two ways: either they enhance the water exchange with the Baltic Sea, or 


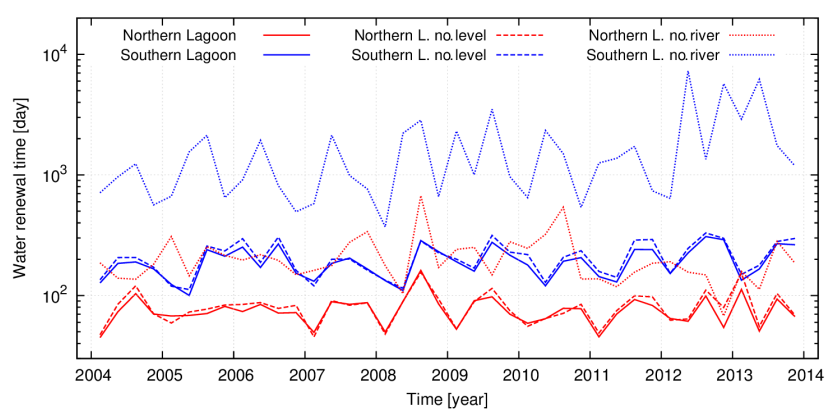

Figure 10. Water renewal times for the northern and southern basin. The WRT is computed every 3 months to obtain a seasonal estimate. WRT is computed for the reference run (continuous line), with no water level variation in the Baltic Sea (dashed line), and with no river discharge (dotted line). The results for the no baroclinic run are not shown because they are basically identical to the reference simulation. The northern lagoon is in red, the southern lagoon in blue.

they contribute to the internal mixing and redistribution of the water masses inside the lagoon.

The influence of the Nemunas on the internal water circulation is quite low, and it only marginally influences the exchanges between the southern and northern part. The $\mathrm{Ne}$ munas contributes mostly to kinetic energy under lower discharges, but with high discharges a water level gradient is building up and potential energy is becoming the major energy contribution. The discharge where potential and kinetic energy become similar is at around $900 \mathrm{~m}^{3} \mathrm{~s}^{-1}$, which is close to the climatological average of the river discharge of $700 \mathrm{~m}^{3} \mathrm{~s}^{-1}$ (Jakimavičius, 2012). Therefore average kinetic and potential energy due to the Nemunas discharge are nearly equi-distributed.

The pattern of the WRT distribution between different seasons is very similar between each other. The absolute numbers depend on the season, with spring showing low WRT close to the Nemunas outflow and highest WRT in the southern basin during summertime. This confirms the strong influence of the Nemunas forcing on the WRT, especially in the northern basin.

The inter-annual changes of the WRT show a coherent picture. Lowest WRTs are always during winter and spring, and highest during summer (Fig. 8). The variability is much lower in the northern basin, where the inflow of the Nemunas is stabilizing the water exchange. On the other hand, the only physical forcing in the southern basin is the meteorological forcing which may vary considerably between different years. As can be seen from the figure, the summers of 2006, 2008, 2009, and 2012 show large WRTs in the southern basin, whereas the northern part only showed a minor increase due to the higher importance of the Nemunas discharge.

It might also be interesting to compare the values of the total WRT (152 days) to a gross estimate of freshwater in-

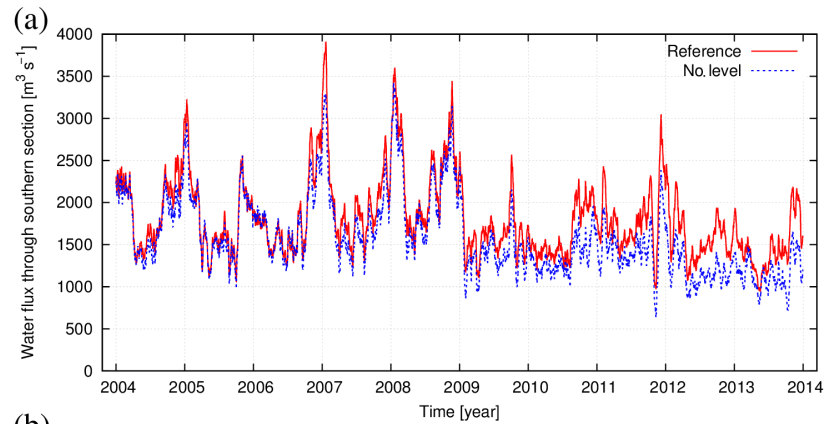

(b)

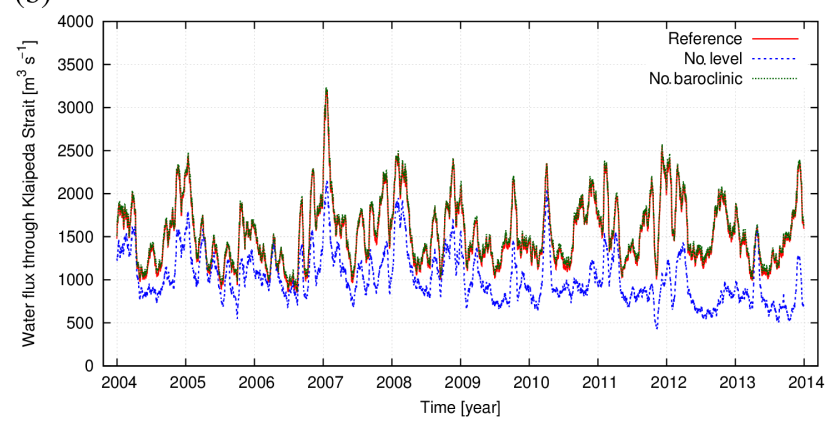

Figure 11. Absolute fluxes through the south section (a) and through the Klaipeda Strait (b). Results are shown for the reference run compared to the simulation with no water level forcing in the Baltic Sea. In the case of Klaipeda Strait also the fluxes computed with the non-baroclinic case have been added.

flow into the lagoon. The relevant indicator is the flushing time, computed by dividing the volume of the lagoon by the freshwater fluxes. This flushing time gives the lowest possible time of exchange, when considering complete mixing with the lagoon waters. Inserting the numbers for the average riverine discharges and the average rainfall, the flushing time is about 110 days for the lagoon. This flushing number still does not take into account the fluxes with the Baltic Sea. This indicates a mixing efficiency of 0.7 . Taking into account also the fluxes through the Klaipeda Strait, this number will be even lower, and well in the range of other lagoons (Umgiesser et al., 2014).

Ice cover, even if important for the exchange in the inside of the lagoon, does not influence too much the WRT. As explained above, most of the time when ice is present, it is land locked, therefore inhibiting completely the momentum transfer between the atmosphere and the water. Only during strong winters, when ice cover is lasting for a considerable amount of time, the ice cover will be able to change the WRT. Two different effects can be seen. While the WRT increases in the south, in the north it decreases. This can be explained by the fact that water exchange between the north and the south is decreasing. Less fresh water from the Nemunas goes to the south, increasing the WRT there. However, the fresh water that stays in the north contributes to lower WRTs there. Summarizing, the WRT in the whole basin is changing very little, showing that ice cover may inhibit the exchanges inside 
the lagoon, but it does not too much influence the exchanges with the Baltic Sea.

Other physical factors that may influence the WRT distribution are water level variations in the Baltic Sea and the Nemunas discharge. Switching off the water level variation did result in slightly smaller WRTs in the basin (7-8\%), and exchanges between the southern and northern basin were decreasing by around $10 \%$. Again this result is astonishing. Most lagoons throughout the world are dominated by tidal exchange. Even in Mediterranean lagoons, where tides can be classified as micro-tidal, it is still the tide which mostly controls the exchange with the open sea (Umgiesser et al., 2014). However, in the eastern Baltic Sea tides are negligible, and intermittent water level changes are not strong enough (or not frequent enough) to influence the water exchange with the Baltic Sea.

The strongest impact on the WRT distribution is exerted by the Nemunas inflow. The northern part of the lagoon shows WRTs of around 7 months, whereas the in the southern part the WRT increases to around 5 years on average between the years. As already mentioned this is only due to the missing freshwater input of the Nemunas and not to any other mechanisms. If we compare the exchanges between the northern and southern basin, we can see that with respect to the reference simulation the exchange only decreases by about $2 \%$. Without the Nemunas discharge there is therefore still enough exchange between the basins. However, since there is no fresh water in the northern part, there is also nothing to be exchanged that might lower the WRTs in the south.

In the last simulation we tested the contribution of the twolayer density flow through the Klaipeda Strait to the WRT distribution. The results indicate a negligible effect of the baroclinic flow. This is mainly due to three causes. The first is the fact that two-layer flow exists only in case of low barotropic forcing. Therefore, when strong Nemunas discharge is active, or when water level fluctuations in the Baltic Sea are important, the two-layer flow is destroyed. This was one of the main findings in Zemlys et al. (2013). The second cause is the existence of a sill just inside the Curonian Lagoon, where the depth of the strait drops from $15 \mathrm{~m}$ in the strait to $5 \mathrm{~m}$ in the lagoon. The salt water normally does not get over this sill but is trapped outside in the strait. Finally, the third reason that the baroclinic acceleration is less important is the fact that salinity gradients in the Baltic Sea are much weaker than in normal cases. Whereas in other oceans the salinity gradient in the estuary is up to $35 \%$, here in the eastern Baltic Sea it is only $7 \%$.

Summarizing, the study has shown that the most important physical forcing that influences the WRT in the Curonian Lagoon is the Nemunas discharge. Other mechanisms influence only the strength of exchange inside the lagoon, but they do not really contribute to the exchange with the Baltic Sea. This is especially true for the ice cover, which influences the overall WRT only marginally. Therefore, if climate change effects have to be taken into account, WRT changes will be more likely influenced by changing Nemunas discharges than by change in ice cover.

Acknowledgements. This study was funded by European Social Fund under the Global Grant measure (CISOCUR project VP13.1-ŠMM-07-K-02-086). It has also been carried out under the framework of the RITMARE Flagship Project, funded by MIUR under the NRP 2011-2013. The authors thank the Swedish Meteorological and Hydrological Institute the access to HIROMB data that were used in this study as boundary conditions, the Lithuanian Hydrometeorological service for data required as meteorological and hydrological forcing, and the Marine Research department of Environmental Protection Agency of Lithuania for permanent monitoring data.

Edited by: L. Kantha

\section{References}

Andutta, P. F., Ridd, P. V., Deleersnijder, E., and Prandle, D.: Contaminant exchange rates in estuaries - New formulae accounting for advection and dispersion, Prog. Oceanogr., 120, 139-153, 2014.

Bellafiore, D., Guarnieri, A., Grilli, F., Penna, P., Bortoluzzi, G., Giglio, F., and Pinardi, N.: Study of the hydrodynamical processes in the Boka Kotorska Bay with a finite element model, Dynam. Atmos. Oceans, 52, 298-321, 2011.

Burchard, H. and Petersen, O.: Models of turbulence in the marine environment - a comparative study of two equation turbulence models. J. Mar. Syst., 21, 29-53, 1999.

Cardellicchio, N., Annicchiarico, C., Di Leo, A., Giandomenico, S., and Spada, L.: The Mar Piccolo of Taranto: an interesting marineecosystem for the environmental problems studies, Environ. Sci. Poll. Res., 1-7, doi:10.1007/s11356-015-4924-6, 2015.

CEC: Directive 2000/60/EC of the European Parliament and of the Council of 23 October 2000 establishing a framework for community action in the field of water policy, J. Eur. Commun., L327, 1-73, 2000.

Cucco, A. and Umgiesser, G.: Modelling the Venice Lagoon residence time, Ecol. Model., 193, 34-51, 2006.

Cucco, A., Umgiesser, G., Ferrarin, C., Perilli, A., Canu, D. M., and Solidoro, C.: Eulerian and lagrangian transport time scales of a tidal active coastal basin, Ecol. Model., 220, 913-922, 2009.

Dailidiené, I. and Davulienè, L.: Salinity trend and variation in the Baltic Sea near the Lithuanian coast and in the Curonian Lagoon in 1984-2005, J. Mar. Syst., 74, 20-29, 2008.

Davulienė, L., Dailidienè, I., Dick, S., Trinkūnas, G., and Valkūnas, L.: Validation of the circulation model for Lithuanian coastal waters, J. Environ. Chem. Phys., 24, 226-231, 2002.

De Pascalis, F., Pérez-Ruzafa, A., Gilabert, J., Marcos, C., and Umgiesser, G.: Climate change response of the Mar Menor coastal lagoon (Spain) using a hydrodynamic finite element model, Estuar. Coast. Shelf Sci., 114, 118-129, doi:10.1016/j.ecss.2011.12.002, 2012.

Fairall, C. W., Hare, J. E., Grachev, A. A., and Edson, J. B.: Bulk parameterization of air-sea fluxes: Updates and verification for the COARE algorithm, J. Climate, 16, 571-591, 2003. 
Ferrarin, C. and Umgiesser, G.: Hydrodynamic modeling of a coastal lagoon: The Cabras lagoon in Sardinia, Italy, Ecol. Model., 188, 340-357, 2005.

Ferrarin, C., Razinkovas, A., Gulbinskas, S., Umgiesser, G., and Bliudziute, L.: Hydraulic regime-based zonation scheme of the Curonian Lagoon, Hydrobiologia, 611, 133-146, 2008.

Ferrarin, C., Umgiesser, G., Bajo, M., Bellafiore, D., De Pascalis, F., Ghezzo, M., Mattassi, G., and Scroccaro, I.: Hydraulic zonation of the lagoons of Marano and Grado, Italy. A modelling approach, Estuar. Coast. Shelf Sci., 87, 561-572, 2010.

Ferrarin, C., Ghezzo, M., Umgiesser, G., Tagliapietra, D., Camatti, E., Zaggia, L., and Sarretta, A.: Assessing hydrological effects of human interventions on coastal systems: numerical applications to the Venice Lagoon, Hydrol. Earth Syst. Sci., 17, 1733-1748, doi:10.5194/hess-17-1733-2013, 2013.

Funkquist, L.: A unified model system for the Baltic Sea, Elsevier Oceanogr. Ser., 69, 516-518, doi:10.1016/S04229894(03)80082-X, 2003.

Gonenc, I. E. and Wolflin, J. P.: Coastal Lagoons: Ecosystem Processes and Modeling for Sustainable Use and Development, CRC Press, Boca Raton, FL, USA, 2005.

Jakimavičius, D.: Changes of water balance elements of the Curonian Lagoon and their forecast due to anthropogenic and natural factors, Doctor thesis, Kaunas, 2012.

Lucas, L. V., Thompson, J. K., and Brown, L. R.: Why are diverse relationships observed between phytoplankton biomass and transport time?, Limnol. Oceanogr., 54, 381-390, 2009.

McLusky, D. S. and Elliott, M.: The Estuarine Ecosystem: Ecology, Threats and Management, OUP, Oxford, 214 pp., 2004.

Radziejewska, T. and Schernewski, G.: The Szczecin (Oder-) Lagoon, in: Ecology of Baltic Coastal Waters, edited by: Schiewer, U., Springer-Verlag, Berlin Heidelberg, 115-130, 2008.
Raudsepp, U. and Kouts, T.: Wind driven circulation the Curonian Lagoon, Environ. Chem. Phys., 24, 151-155, 2002.

Takeoka, H.: Fundamental concepts of exchange and transport time scales in a coastal sea, Cont. Shelf Res., 3, 311-326, 1984.

Umgiesser, G. and Cucco, A.: Computation of Transport Time Scales through Numerical Modeling, in: Geomatic Solutions for Coastal Environments, edited by: Maanan, M. and Robin, M., Nova Science Publishers, New York, 243-262, 2011.

Umgiesser, G., Melaku Canu, D., Cucco, A., and Solidoro, C.: A finite element model for the Venice Lagoon. Development, set up, calibration and validation, J. Mar. Syst., 51, 123-145, 2004.

Umgiesser, G., Ferrarin, C., Cucco, A., De Pascalis, F., Bellafiore, D., Ghezzo, M., and Bajo, M.: Comparative hydrodynamics of 10 Mediterranean lagoons by means of numerical modeling. J. Geophys. Res.-Oceans, 119, 2212-2226, doi:10.1002/2013JC009512, 2014.

Vadineanu, A., Cristofor, S., Ignat, G. H., Romanca, G., Ciubuc, C., and Florescu, C.: Changes and opportunities for integrated management of the Razim-Sinoe Lagoon System, in: International Journal of Salt Lake Research, Kluwer Academic Publishers, Amsterdam, the Netherlands, 135-144, 1997.

Žaromskis, R.: Oceans, Seas, Estuaries, Debesija, Vilnius, 1996.

Zemlys, P., Ferrarin, C., Umgiesser, G., Gulbinskas, S., and Bellafiore, D.: Investigation of saline water intrusions into the Curonian Lagoon (Lithuania) and two-layer flow in the Klaipeda Strait using finite element hydrodynamic model, Ocean Sci., 9, 573-584, doi:10.5194/os-9-573-2013, 2013. 